NASA/TM-2000-210232

\title{
A Deep Space Power System Option Based on Synergistic Power Conversion Technologies
}

Jeffrey G. Schreiber

Glenn Research Center, Cleveland, Ohio

Prepared for the

2000 Space Technology and Applications International Forum

sponsored by the American Institute of Physics

Albuquerque, New Mexico, January 30-February 3, 2000

National Aeronautics and

Space Administration

Glenn Research Center

July 2000 
This report contains preliminary findings, subject to revision as analysis proceeds.

Available from

NASA Center for Aerospace Information 7121 Standard Drive

Hanover, MD 21076

Price Code: A03
National Technical Information Service 5285 Port Royal Road Springfield, VA 22100

Price Code: A03 


\title{
A Deep Space Power System Option Based On Synergistic Power Conversion Technologies
}

\author{
Jeffrey G. Schreiber \\ National Aeronautics and Space Administration \\ Glenn Research Center \\ Cleveland, Ohio 44135
}

\begin{abstract}
Deep space science missions have typically used radioisotope thermoelectric generator (RTG) power systems. The RTG power system has proven itself to be a rugged and highly reliable power system over many missions, however the thermal-to-electric conversion technology used was approximately $5 \%$ efficient. While the relatively low efficiency has some benefits in terms of system integration, there are compelling reasons why a more efficient conversion system should be pursued. The cost savings alone that are available as a result of the reduced isotope inventory are significant. The Advanced Radioisotope Power System (ARPS) project was established to fulfill this goal. Although it was not part of the ARPS project, Stirling conversion technology is being demonstrated with a low level of funding by both NASA and DOE. A power system with Stirling convertors, although intended for use with an isotope heat source, can be combined with other advanced technologies to provide a novel power system for deep space missions. An inflatable primary concentrator would be used in combination with a refractive secondary concentrator (RSC) as the heat source to power the system. The inflatable technology as a structure has made great progress for a variety of potential applications such as communications reflectors, radiators and solar arrays. The RSC has been pursued for use in solar thermal propulsion applications, and it's unique properties allow some advantageous system trades to be made. The power system proposed would completely eliminate the isotope heat source and could potentially provide power for science missions to planets as distant as Uranus. This paper will present the background and developmental status of the technologies and will then describe the power system being proposed.
\end{abstract}

\section{INTRODUCTION}

The Thermo-Mechanical Systems branch at the NASA Glenn Research Center is responsible for developing a wide variety of advanced technologies for future spacecraft. Among the technologies that are currently being pursued are 1) free-piston Stirling convertors for potential use with a radioisotope heat source to provide power for deep space exploration, 2) inflatable solar concentrators that may potentially be used for earth orbiting solar thermal systems, and 3) a novel refractive secondary concentrator (RSC) intended primarily for solar thermal propulsion. For each one of the technologies there exists a clear rationale that shows its value at the system or mission level, for the intended application. These technologies are currently being developed independent of one another since they are targeted at different applications.

Each of the advanced technologies have unique characteristics that make them attractive for the intended applications. The free-piston Stirling convertor has long been considered a candidate for space power applications, in part because of the demonstrated high conversion efficiency, and also because of the potential for long life. Inflatable primary concentrators are used to concentrate incident solar rays to a focal spot. This is essentially the same function performed by solar concentrators in past applications, however the inflatable technology dramatically reduces the specific mass to levels far below those achieved with rigid or deployable concentrators. The RSC utilizes the principle of total internal reflectance and can perform two important functions. First, it can further concentrate the solar flux from a primary concentrator to achieve a higher concentration ratio or temperature, and secondly it can transport the flux deep into a cavity and deposit it with a tailored profile. Each of these technologies will be discussed in more detail later in this paper. 
There has long been interest in developing a power system for deep space exploration that reduces the inventory of the isotope fuel (plutonium) needed, or potentially eliminates the need entirely. The radioisotope thermoelectric generator (RTG) used in the past has proven itself to be very rugged and highly reliable, however the relatively low conversion efficiency requires a large inventory of plutonium contained in the General Purpose Heat Source (GPHS) blocks. For reasons of environmental concerns and mission cost, a highly efficient conversion system requiring less plutonium, or possibly eliminating the plutonium would be highly desirable. One system investigated in the past was the power antenna (Cassapakis, 1996. Lichodziejewski, 1999) which used an inflatable parabolic reflector that served two purposes. It functioned as a reflector for the communications system, and also as a solar reflector for the power system. The power conversion technology used was a photovoltaic array situated in concentrated sun light, in the general region of the focal spot. Through a NASA SBIR, L'Garde investigated this option and proposed that it had merit for low power missions, potentially to Jupiter (5.2 AU) and Saturn (9.5 AU).

A system was conceived at the NASA Glenn Research Center (GRC) that integrates a free-piston Stirling power conversion system intended to be used with GPHS blocks, an inflatable primary concentrator, and the RSC into a relatively low power level (less than $1 \mathrm{kWe}$ ) solar dynamic power system. It is believed that with careful consideration, a system could be configured that exploits the strengths of each of the technologies and provides a viable isotope-free power system option for space science missions. After conceptualizing the system, a brief study was performed that indicated that the system indeed may be advantageous for some space exploration missions (Mason, 2000). A key attribute of the system proposed is that all of the subsystems are currently being developed under existing projects, and that the system was conceived by recognizing the synergism that existed in these previously unrelated projects.

\section{THE TECHNOLOGIES}

A brief description will be given of each of the technologies that have been incorporated into the proposed solar Stirling power system. The description will include the characteristics of the technology, a description of the intended applications, and an indication of the status of development.

\section{Radioisotope Stirling Conversion System}

The Department of Energy (DOE) and NASA GRC are developing a Stirling convertor as a possible high efficiency radioisotope electric power system option for future space exploration. A 1997 study team with joint participation from NASA and DOE determined that the Stirling conversion option was a low risk alternative with dependable background of materials, lifetime, and demonstrated performance (Frazier, 1998, Mondt, 1998). The Advanced Radioisotope Power System (ARPS) project was initiated and went forward with the Alkali Metal Thermal to Electric Converter (AMTEC) as the conversion technology. Subsequently, a low level effort investigating the feasibility of the free-piston Stirling convertor was initiated (Thieme, 1999, White 1999). This was performed primarily through a DOE contract with the Stirling Technology Company (STC) of Kennewick, WA, however it was also supported by NASA GRC through Small Business Innovation Research (SBIR) contracts in addition to GRC in-house capabilities. This effort has resulted in operational 55 We free-piston Stirling Technology Demonstrator Convertors (TDC), which have demonstrated full power operation and predicted efficiency. The convertors are shown in figures 1 and 2 . The technologies used in these $55 \mathrm{We}$ convertors have previously been used by STC in other convertors that have demonstrated long life with over 53,000 hours of continuous operation with no measurable degradation.

As work has progressed on the $55 \mathrm{We}$ TDC, many of the previously unresolved concerns regarding free-piston Stirling convertors have been

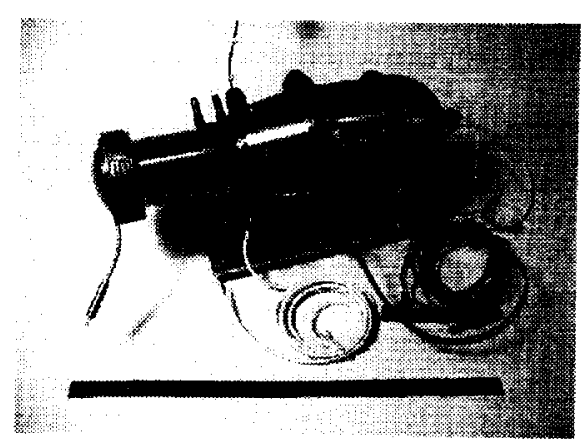

Figure 1. A 55 We Free-Piston Stirling Technology Demonstrator Convertor. 
addressed. Synchronous operation has been demonstrated with multiple convertors that are mechanically independent. Synchronous operation of pairs of convertors leads to a dynamically balanced system with very low residual vibration. An Advanced Vibration Reduction System (AVRS) is also being developed to further reduce vibration (Thieme, 2000). Preliminary results from recent tests and analysis indicate that residual vibration is within acceptable levels for space science missions. With the Stirlng convertor technology for this application progressing, attention is starting to focus on system integration issues. Orbital Science Corporation (OSC) has developed a system concept (Schock, 1999). One of the early system concepts developed by OSC is shown in figure 3. Under contract to DOE, Lockheed Martin Astronautics, Valley Forge, PA, is also developing system concepts.

In the concept shown, an insulated cavity exists in the center of the structure where the GPHS blocks would be secured. The housing acts as a structure to which the Stirling convertors are mounted, however it also contains the multi-layer insulation (MLI) that surrounds the GPHS blocks. Although other configurations are being studied, the highly insulated structure for the GPHS blocks is a common feature.

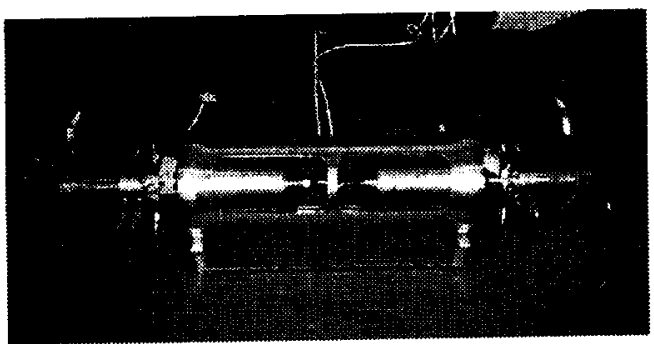

Figure 2. A Pair of 55 We Stirling Convertors Demonstrating Low Vibration Operation.

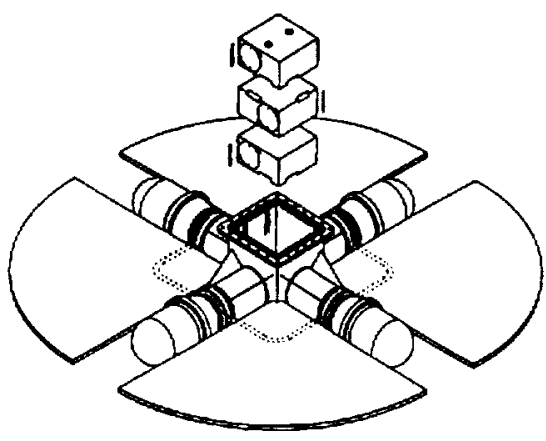

Figure 3. Radioisotope Stirling Power System Concept Proposed by Orbital Science Corporation.

\section{Solar Concentrators}

The NASA GRC has had a longstanding interest in the development of advanced, lightweight solar concentrators Efforts at GRC date back to the early 1960's with the development of deployable concentrators with rigid facets. An early effort working with TRW produced a deployable concentrator knows as the Sunflower because of the arrangement of the hinged pedals that deployed to form the concentrator. A subsequent effort at GRC in 1965 produced a 6 meter diameter magnesium concentrator with a specific mass of $4.7 \mathrm{~kg} / \mathrm{m}^{2}$. In the early stages of Space Station Freedom (SSF), one of the power system options was a hybrid system including both photovoltaic and solar dynamic power conversion. In 1989, a concentrator was developed for SSF based on a box-beam supporting structure with multiple triangular facets. The 456 facets in this design, without the supporting box beam structure, had a specific mass of $2.4 \mathrm{~kg} / \mathrm{m}^{2}$. In 1994 a system level test was performed with a downsized version of the SSF concentrator, as shown in figure 4 , which had a mass of approximately $10 \mathrm{~kg} / \mathrm{m}^{2}$.

Lightweight deployable designs, such as the Spline Radial Panel concentrator proposed by Harris Corporation, could reduce the mass to approximately $2 \mathrm{~kg} / \mathrm{m}^{2}$, however this technology has not been demonstrated as a solar concentrator. Thin film inflatable technology offers the potential to reduce the mass of solar concentrators even further, to less than $1 \mathrm{~kg} / \mathrm{m}^{2}$. There is current interest in inflatable technology for a

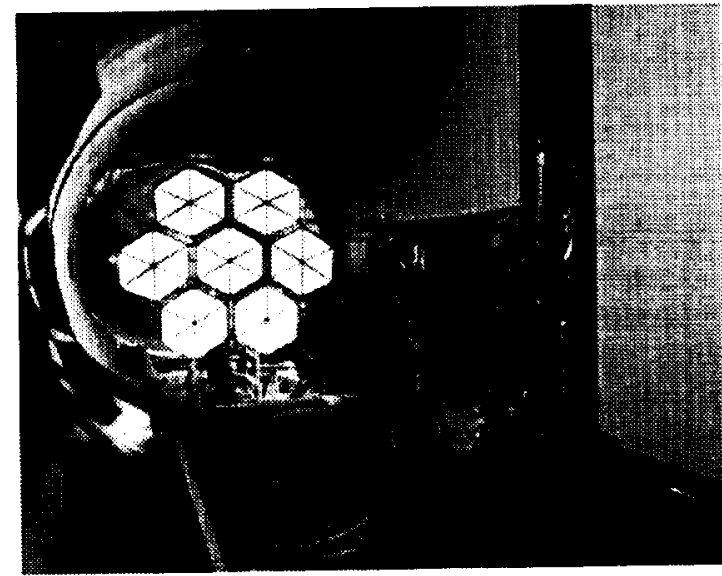

Figure 4. A Rigid Concentrator Used During The Brayton Solar Dynamic Power System Test at GRC. 
number of applications, of which the inflatable solar concentrator is one. Companies such as SRS Technologies, ILC Dover. UAT, and L'Garde are developing concepts for large thin film inflatable solar concentrators. The demonstration of the Inflatable Antenna Experiment by L'Garde in 1994, as shown in figure 5, was a major step forward in demonstrating the potential of this technology. Inflatables had previously flown in space. however this was the first demonstration in space of a parabolic reflector supported by a taurus and struts.

There is also interest in using light weight concentrators for solar thermal propulsion systems (Partch, 1999). Solar thermal propulsion provides an option for orbit transfer and in-space maneuvers with a trade off in specific impulse and thrust levels, each being somewhere between those levels achieved with chemical propulsion and electric propulsion. This application requires a temperature well in excess of $2000 \mathrm{~K}$ in the solar receiver cavity. The optical accuracy requirements levied on the inflatable concentrator are very demanding and are one of the key elements being addressed in current efforts.

Recognizing that the requirements placed on a solar concentrator for either solar thermal propulsion or solar thermal power are similar, GRC began coordinating efforts with the Air Force Research Laboratory (AFRL) in the development of inflatable concentrators. A Phase I SBIR contract with SRS Technologies of Huntsville, AL produced a technology demonstration inflatable concentrator as shown in figure 6. This concentrator was subsequently tested in collaboration with AFRL in the Tank 6 solar thermal vacuum facility at GRC. The concentrator achieved an approximate $2 \mathrm{mrad}$ slope error, which is sufficient accuracy for solar some thermal applications. The Phase II contract has been awarded and the effort is currently underway. While this technology looks promising, many issues such as inflation control, rigidization, and UV tolerance need to be addressed.

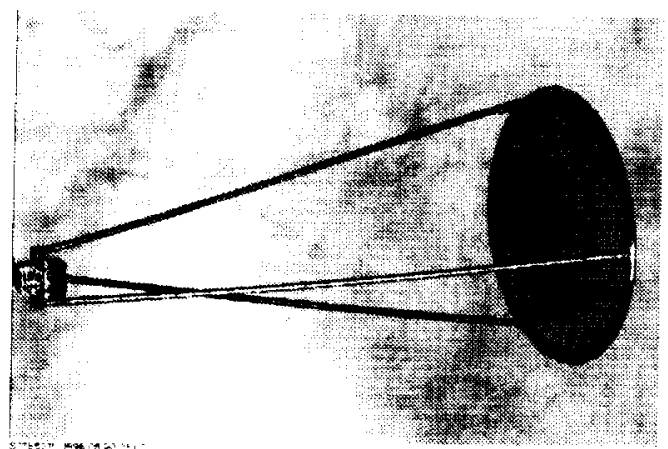

Figure 5. Inflatable Antenna Experiment by L'Garde.

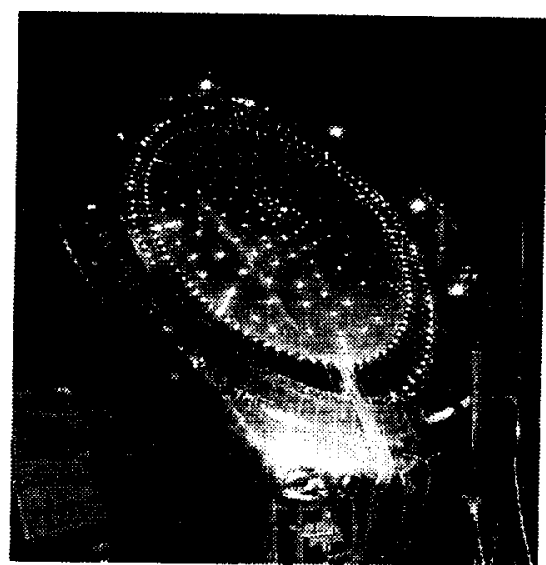

Figure 6. SRS Solar Concentrator Being Installed in GRC Tank 6 for Testing.

\section{Secondary Concentrators}

An effort is underway at NASA GRC to develop a highly efficient secondary solar concentrator. It is based on an innovative, single crystal refractive secondary concentrator (RSC) concept which uses the principle of total intemal reflection. The RSC alleviates some of the limitations of reflective secondary concentrators in terms of concentration ratio, efficiency, and distribution of the flux exiting the concentrator. Concentration ratios of more than 25:1 are possible with the RSC, and efficiency at high power is projected to be $90 \%$ or greater. When used with a high quality primary concentrator, this allows a total concentration ratio (i.e., the primary and secondary concentrators combined) on the order of 10,000:1. A prototype RSC is shown in figure 7.

The RSC designs analyzed and tested thus far perform two distinct functions. First, the conical segment concentrates the light via total internal reflection. Secondly, the extractor can be used to transport the solar flux into a receiver cavity, and the extractor can then be tailored to deliver the flux with a favorable distribution. The ability of the 
extractor to transport the energy deep into the receiver differs from the reflective secondary concentrators which tend to distribute the flux near the aperture of the receiver.

The effort at GRC has been directed primarily toward the use of this technology for solar thermal propulsion where high concentration ratios and high temperature in the receiver are necessary. This effort was initiated in support of the Shooting Star solar thermal propulsion experiment proposed by the NASA Marshall Space Flight Center. Other applications would be for solar thermal furnaces and possibly for solar thermal power conversion. While this work is in its early stages, the results are very promising (Wong, 1999). The use of the RSC has a significant impact on the primary concentrator. For example, in an optimized system the accuracy requirements on the primary concentrator may be able to be relaxed, and a mass or cost savings may be realized.

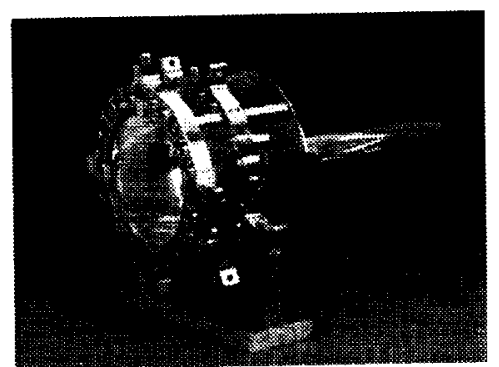

Figure 7. Refractive Secondary Concentrator at GRC.

\section{THE SOLAR STIRLING POWER SYSTEM}

The ARPS program is based on the desire of both NASA and DOE to have an advanced radioisotope power system with higher efficiency than the RTGs, and thus requiring less plutonium. Extending this logic would lead one to try to develop a power system for deep space missions that needs no plutonium at all. Such a system was envisioned at GRC by integrating the technologies that were discusses earlier in this paper; that is, a system with a lightweight inflatable primary concentrator, a high efficiency refractive secondary concentrator, and a high efficiency free-piston Stirling conversion system. Compared to solar dynamic power systems that have been studied and tested in the past (Mason, 1999), the proposed system has some distinctive characteristics. By considering the unique traits of the individual technologies, system level trades were able to be performed that are different than experienced in previous systems.

By taking advantage of the high concentration ratio and high efficiency of the RSC, the accuracy requirements levied on the primary concentrator can be relaxed. This feature should result in savings in terms of both mass and cost. System level analysis is necessary to determine the final configuration of the optical concentration system, i.e. the primary and secondary concentrators as a system. The RSC also incorporates an extractor which can take the solar energy deep into a cavity, and deposit it in a predetermined distribution. This solar concentration system would then be integrated with a free-piston Stirling based power conversion system. The power conversion system would be a derivative of the system being investigated for use with GPHS blocks, however the cavity intended to hold the GPHS blocks would be modified to act as a solar receiver cavity. The extractor of the RSC would take the solar flux into a cavity designed for the GPHS blocks, however the cavity would now be heated with the solar energy. An initial study concluded that a $200 \mathrm{~W}$ solar Stirling system of the type described is competitive with radioisotope power systems out to $10 \mathrm{AU}$ and is projected to have a specific power of $5.9 \mathrm{~W} / \mathrm{kg}$ in this size range (Mason, 2000). A further extension of the system would use the primary concentrator as proposed in the study of the power antenna, and thus it would perform duties for both the power system and the communication system.

The proposed system leads to a highly integrated spacecraft which might be suitable for a range of deep space missions. Missions to Mars may very well be served with a photovoltaic power system because the solar intensity is still relatively high. Similarly, missions to Neptune or Pluto may require unreasonably large primary concentrators because of the extremely low solar intensity, and thus may be better served with a high efficiency isotope power system. It is believed however, that there may be a range of missions which could benefit from using the proposed non-isotope power system. If these missions are able to be performed using the proposed power system, then there are great benefits incurred because of the elimination of the isotope fuel. These benefits, based on the elimination of the isotope fuel, are in terms of both environmental concerns and cost. The cost savings is believed to be on the order of 10 's of millions of dollars per mission. 


\section{CONCLUDING REMARKS}

While a detailed study of this concept has not been performed, an initial investigation indicates that this solar powered conversion system would be a viable option for missions out to Jupiter and Saturn and possibly Uranus. Advances in each of the technologies are needed; the primary concentrator must demonstrate low mass and life for the candidate missions, the RSC must demonstrate high power throughput, and the integrated system utilizing existing Stirling convertors must be developed. While it is recognized that each one of these technologies requires further development before it is available to be used in the proposed power system, it should also be pointed out that each one of the technologies needed in this system are currently being developed under separate, existing programs. The system is not proposed as a solution for all missions. however if some of the typical missions that had previously used isotope fueled power systems could now be flown without any isotope for power, the benefits are substantial.

\section{REFERENCES}

Frazier. T.A.: "Advanced Conversion Technology Review Panel Report," Proceedings of the 33rd Intersociety Energy Conversion Engineering Conference, Paper IECEC-98-39, 1998.

Cassapakis, C., and Thomas, M.: "A Power Antenna for Deep Space Missions," in Solar Engineering, edited by J. H. Davidson et al., ASME Conference Proceedings, Book Number H01046, 1996.

Lichodziejewski, D., and Cassapakis, C.: "Inflatable Power Antenna Technology," AIAA Paper 99-1074, American Institute of Aeronautics and Astronautics, 1999.

Mason. L.S.: "Technology Projections for Solar Dynamic Power," NASA TM-1999-208851, 1999.

Mason. L.S.: "Solar Stirling for Deep Space Applications," in Space Technology and Applications International Forum, edited by M. S. El-Genk, AIP Conference Proceedings, American Institute of Physics, 2000.

Mondt, J.F., and Nesmith, B.J.: "Advanced Convertor Technology Evaluation and Selection for ARPS," in Space Technology and Applications International Forum, edited by M. S. El-Genk, AIP Conference Proceedings, American Institute of Physics, 1998.

Partch, R.E., Holmes, M.R., and Pearson. J.C.: "Inflatable Concentrator Performance Characterization for Space Flight Applications," in Renewable and Advanced Energy Systems for the $21^{\text {st }}$ Century, American Society of Mechanical Engineering, Maui, 1999.

Schock. Alfred, Or, Chuen, and Kumar, Vasanth: "Radioisotope Power System Based on Improved Derivative of Existing Stirling Engine and Alternator," in Space Technology and Applications International Forum, edited by M. S. El-Genk, AIP Conference Proceedings, American Institute of Physics, 1999.

Thieme, L.G.. Qiu, S., and White, M.A.: "Technology Development for a Stirling Radioisotope Power System for Deep Space Missions," Proceedings of the $34^{\text {th }}$ Intersociety Energy Conversion Engineering Conference, Society of Automotive Engineers, 1999, Paper IECEC-99-01-2454.

Thieme, L.G.. Qiu. S., and White, M.A.: "Technology Development for a Stirling Radioisotope Power System," in Space Technology and Applications International Forum, edited by M. S. El-Genk, AIP Conference Proceedings. American Institute of Physics, 2000.

White, M.A., Qiu, S, Olan, R.W., and Erbeznik, R.M.: "Technology Demonstration of a Free-Piston Stirling Advanced Radioisotope Space Power System," in Space Technology and Applications International Forum, edited by M. S. El-Genk, AIP Conference Proceedings, American Institute of Physics, 1999.

Wong. Wayne A., and Macosko, Robert P.: "Refractive Secondary Concentrators for Solar Thermal Applications," NASA TM-1999-209379, 1999. 
Public reporting burden for this collection of information is estimated to average 1 hour per response, including the time for reviewing instructions, searching existing data sources. collection of information, including suggestions for reducing this reviewing the coliection of information. Send comments regarding this burden estimate or any other aspect of this Davis Highway, Suite 1204 . Arlingtong $V$ A Davis Highway, Suite 1204, Arlington, VA 22202-4302, and to the Ottice of Management and Budget. Paperwork Reduction Project (0704-0188), Washington, DC 20503.

\begin{tabular}{l|l|l|}
\hline 1. AGENCY USE ONLY (Leave blank) & 2. REPORT DATE & 3. REPORT TYPE AND DATES COVERED
\end{tabular}

4. TITLE AND SUBTITLE July 2000

Technical Memorandum

A Deep Space Power System Option Based on Synergistic Power Conversion Technologies

6. AUTHOR(S)

Jeffrey G. Schreiber

7. PERFORMING ORGANIZATION NAME(S) AND ADDRESS(ES)

National Aeronautics and Space Administration

John H. Glenn Research Center at Lewis Field

Cleveland, Ohio 44135-3191

8. PERForming ORganization REPORT NUMBER

$\mathrm{E}-12352$

9. SPONSORINGMONITORING AGENCY NAME(S) AND ADDRESS(ES)

National Aeronautics and Space Administration

Washington, DC 20546-0001

WU-839-20-00-00

5. FUNDING NUMBERS AGENCY REPORT NUMBER

NASA TM-2000-210232

\section{SUPPLEMENTARY NOTES}

Prepared for the 2000 Space Technology and Applications International Forum sponsored by the American Institute of Physics. Albuquerque, New Mexico, January 30-February 3, 2000. Responsible person, Jeffrey G. Schreiber, organization code 5490, (216) 433-6144.

12a. DISTRIBUTIONAVAILABILITY STATEMENT

Unclassified - Unlimited

Subject Category: 20

Distribution: Nonstandard

This publication is available from the NASA Center for AeroSpace Information. (301) 621-0390.

13. ABSTRACT (Maximum 200 words)

Deep space science missions have typically used radioisotope thermoelectric generator (RTG) power systems. The RTG power system has proven itself to be a rugged and highly reliable power system over many missions, however the thermal-to-electric conversion technology used was approximately $5 \%$ efficient. While the relatively low efficiency has some benefits in terms of system integration, there are compelling reasons why a more efficient conversion system should be pursued. The cost savings alone that are available as a result of the reduced isotope inventory are significant. The Advanced Radioisotope Power System (ARPS) project was established to fulfill this goal. Although it was not part of the ARPS project. Stirling conversion technology is being demonstrated with a low level of funding by both NASA and DOE. A power system with Stirling convertors, although intended for use with an isotope heat source, can be combined with other advanced technologies to provide a novel power system for deep space missions. An inflatable primary concentrator would be used in combination with a refractive secondary concentrator (RSC) as the heat source to power the system. The inflatable technology as a structure has made great progress for a variety of potential applications such as communications reflectors, radiators and solar arrays. The RSC has been pursued for use in solar thermal propulsion applications, and it's unique properties allow some advantageous system trades to be made. The power system proposed would completely eliminate the isotope heat source and could potentially provide power for science missions to planets as distant as Uranus. This paper will present the background and developmental status of the technologies and will then describe the power system being proposed.

\section{SUBJECT TERMS}

Stirling engines; Solar energy conversion; Solar collectors

\begin{tabular}{|c|c|c|}
\hline $\begin{array}{c}\text { 17. SECURITY CLASSIFICATION } \\
\text { OF REPORT } \\
\text { Unclassified }\end{array}$ & $\begin{array}{c}\text { 18. SECURITY CLASSIFICATION } \\
\text { OF THIS PAGE } \\
\text { Unclassified }\end{array}$ & $\begin{array}{c}\text { 19. SECURITY CLASSIFICATION } \\
\text { OF ABSTRACT } \\
\text { Unclassified }\end{array}$ \\
\hline
\end{tabular}

NSN 7540-01-280-5500

\begin{tabular}{|c|c|}
\hline & $\begin{array}{c}\text { 15. NUMBER OF PAGES } \\
12\end{array}$ \\
\hline & $\begin{array}{r}\text { 16. PRICE CODE } \\
\mathrm{A03}\end{array}$ \\
\hline $\begin{array}{l}\text { 19. SECURITY CLASSIFICATION } \\
\text { OF ABSTRACT } \\
\text { Unclassified }\end{array}$ & 20. LIMITATION OF ABSTRACT \\
\hline
\end{tabular}


ב- ב 


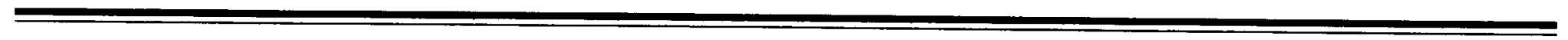

